\title{
A Framework for Sustainable Circular Business Model Innovation
} Maria Antikainen and Katri Valkokari

\author{
"Sustainability is not a luxury;") \\ it is a basic human right. \\ Jim McClelland \\ Editor, journalist, and futurist
}

\begin{abstract}
The circular economy concept is a novel economic model aiming to foster sustainable economic growth, boost global competitiveness, and generate new jobs. In order to make the circular economy mainstream, radical and systemic innovation is needed. Currently, a majority of the business modelling tools and methods lack at least some of the identified and needed elements for innovating business models in a circular economy. In this article, we build a framework for sustainable circular business model innovation by adding important perspectives: recognizing trends and drivers at the ecosystem level; understanding value to partners and stakeholders within a business; and evaluating the impact of sustainability and circularity. We present the results of a case study with a startup company, which was designed to test the framework and provide a concrete example of its usage and future development needs.
\end{abstract}

\section{Introduction}

The dominant linear economic model is running out of road, with non-renewable natural resources dwindling and becoming more expensive. The need for a circular economy is evident given that a significant proportion of non-renewable resources is diminishing and natural resource price volatility is increasing (EMF, 2012). Current trends, such as increasing consumption, new generations of consumers, urbanization and employment, tightening legislation, and technological leaps, accelerate the transition to a circular economy. But this is not a new discussion: Lovins and colleagues already stated, in their 1999 article titled "National Capitalism", that business strategies built around the radically more productive use of natural resources will solve many environmental problems at a profit. McDonough and Braungart (2002) continued this discussion in their wellknown book Cradle to Cradle by suggesting that industry should preserve and enrich ecosystems and nature's biological metabolism while also maintaining a safe, productive technical metabolism for the highquality use and circulation of organic and technical nutrients. Similarly, lifecycle thinking and a broad range of lifecycle assessment (LCA) methods have been util- ized for assessing the environmental impacts of a product, service, business, policy, or process (Cooper \& Fava, 2006). Recently, the Ellen MacArthur Foundation (2012) facilitated this discussion about the circular economy, making a major contribution in familiarizing the concept to academics, businesses, legislators, and finally also to consumers. The main challenge is to rethink how to maximize the value of products and materials and this way to contribute to reducing the usage of natural resources and create positive societal and environmental impact (Kraaijenhagen et al., 2016). To accelerate the transition towards a circular economy, the European Union has launched an ambitious Circular Economy Package, which will contribute to "closing the loop" in product lifecycles through greater recycling and re-use, and bring benefits for both the environment and the economy (European Commission, 2016).

In order to enhance the transformation of companies, industries, and whole economies to adapt and succeed in application of a circular economy, a system-wide innovation changing the whole processes of value cremultiple, if not all aspects of the current business models of companies (Stahel, 2014). Changes have to be made 


\title{
A Framework for Sustainable Circular Business Model Innovation
}

\author{
Maria Antikainen and Katri Valkokari
}

ation is often needed, while the circular economy is grounded to the feedback-rich (non-linear) systems (EMF, 2012). In reality, business model innovation is quite often piecemeal or incremental, rather than transformational, fundamental, and system-wide. Systemwide innovations can only be realized in conjunction with related complementary innovations; in other words, these innovations are not autonomous. Thus, the introduction of a single innovation can result in a systemic innovation if it generates or requires changes in one or more areas of a system.

The entire transformation towards a circular economy sets challenges for established companies. In some cases, it might even destroy the usefulness of their existing capabilities, networks, and business models. For instance, how can an economy that does not create waste make sense for businesses of manufacturers or retailers? Both systemic and radical innovations may open up whole new markets and potential applications. In companies, new ideas and technologies are commercialized through their business models (Chesbrough, 2010). It is clear that radical innovations and disruptive business models are needed in order to tackle the current challenges and move towards the circular economy model; one example could be providing a solution such as "mobility as a service" instead of selling means of transport such as cars, motorcycles, etc.

The big question is how to innovate new disruptive business models in this environment when the whole business ecosystem and its dynamics are changing? Excellent examples of disruptive business models based on a sharing economy, such as Uber and Airbnb, are already changing the whole value network. Therefore, the sharing economy and service business have been identified not only as trends that support our transformation towards a circular economy but also a source of huge, still untapped, opportunities for existing companies as well new players. The first step in many cases could be that companies would perceive their customers as users rather than buyers. Transformation from product-orientation towards service-provider in many ways supports reaching the objectives of the circular economy, for example by motivating companies to extend product lifetime by repairing and remanufacturing, and by more efficient use of resources (Tukker \& Tischner, 2006). To understand and support the business world in this transition, deeper understanding of how to develop disruptive circular economy business models is needed. Closing material loops often affects concerning products or services, relationships with customers and partners, and different production pro cesses and revenue models. In other words, new players or changing roles create a need for re-designing existing value networks and related business models. Managing these changes requires companies to engage in a process of circular business model innovation, which starts by designing the elements of business models. The main objective of this study is to provide a framework for circular business model innovation. Thus, the following question is posed: What are the key elements of sustainable circular business model innovation?

In this article, we first define and describe what a sustainable circular business model is and outline the related literature streams. Then, we examine the existing business modelling tools in general, in particular those related to sustainability and a circular economy. After that, we propose our framework for circular economy business model innovation that is tested with one Finnish startup to evaluate their circular economy business model. Finally, we draw conclusions and provide future research paths.

\section{Framework: Business Model Innovation in a Circular Economy}

The circular economy in a nutshell

We presently live in a non-sustainable "Take-MakeWaste" paradigm based on a linear economic model, which causes many environmental problems that will eventually reach a sustainability dead-end as Earth's resources will be overloaded. This obsolete model will be replaced with a circular economy: an industrial system that is restorative or regenerative by intention and design. In brief, a circular economy is a novel economic model in which the focus is to keep materials in use for as long as possible and also to preserve - or even upgrade - their value through services and smart solutions (Figure 1). As a system-level phenomenon, circular economy business models require interaction between all involved actors, including both the core-business network and other stakeholders.

The circular economy will offer extensive business possibilities for both existing and new actors. In a circular economy, the closed loops consist of two supply chains: a forward and a reverse chain. In a reverse chain, a recovered product re-enters the forward chain (Wells \& Seitz, 2005). Possibilities open up, for instance, for businesses that provide solutions and services along the reverse cycle. The service business has already been seen as a superior business model in many ways compared to selling products, and with the mindset of the 


\section{A Framework for Sustainable Circular Business Model Innovation}

\section{Maria Antikainen and Katri Valkokari}

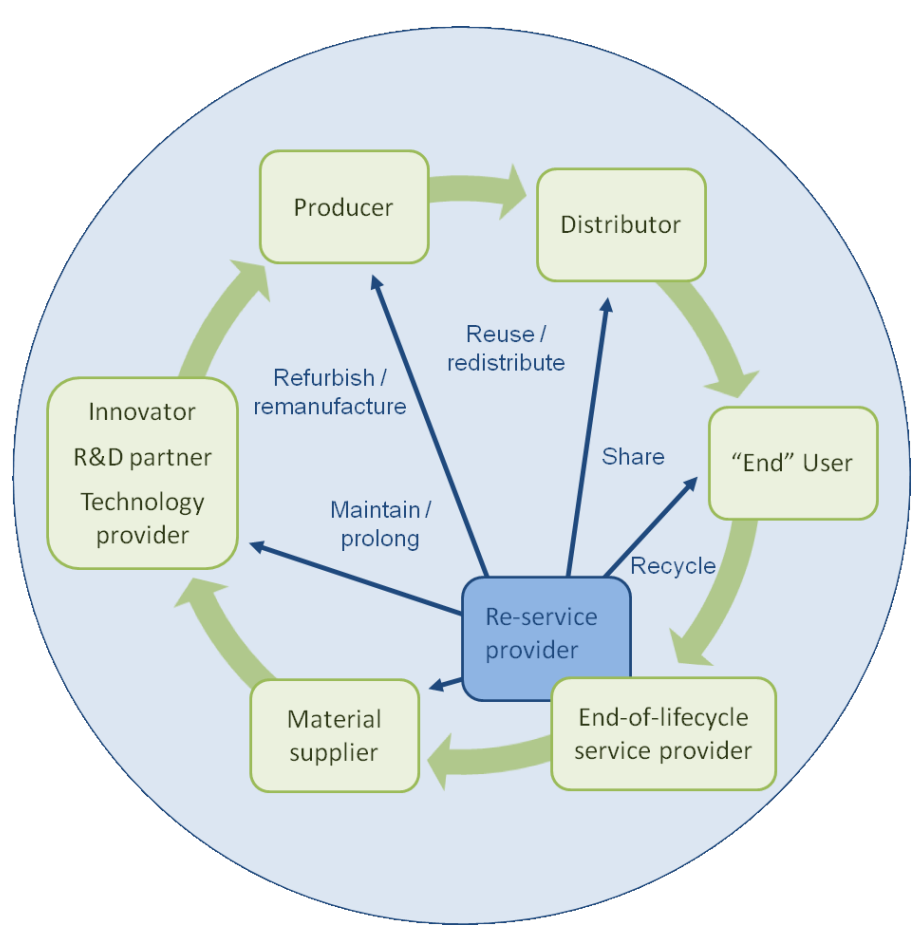

Figure 1. The idea of the circular economy as a feedbackrich (non-linear) system (adapted from Aminoff et al., 2016)

circular economy, the potential is even larger. It can be said that one of the major changes in a circular economy will concern consuming and the role of consumers. The relationships between consumers and products and services will change significantly as the concept of owning will be replaced with buying access and performance. In other words, instead of paying for ownership, consumers will pay per use or pay a fee for monthly access (for example, like the model used by the on-demand Internet streaming media service, Netflix). The transformation towards service businesses can be seen as one of the key solutions in accelerating a circular economy because companies could have incentives to create products that have a long service life, which are used intensively and which are also cost- and material-effective (Tukker \& Tischner, 2006). However, on the negative side of servitization, there might appear the effect called "rebound". The rebound effect refers to a behavioural or other systemic response to a measure taken to reduce environmental impacts that offsets the effect of the measure, for example due to excessive and incorrect use (Hertwich, 2005). Solutions for minimizing this rebound effect are, for instance, co-creation and close relationships with customers in order to build a joint understanding about the importance of enabling a long lifecycle.

\section{Current understanding of a circular economy business model}

A business model represents the rationale of how an organization creates, delivers, and captures value (Osterwalder \& Pigneur, 2010). Business model innovation is the novel way of creating, delivering, and capturing value that is achieved through a change of one or multiple components in the business model (Osterwalder \& Pigneur, 2010). It is apparent that radical innovations and disruptive business models are needed in order to tackle current challenges and move towards the circular economy model (Boons et al., 2013).

Instead of concentrating purely on creating economic value, the literature on sustainable business model innovation concentrates on creating value for a broader range of stakeholders and takes into consideration the benefits from societal and environmental perspectives. Thus, the archetypes of sustainable business models have been identified and named in order to accelerate the development of sustainable business models in practice and theory. The archetypes are: maximize material and energy efficiency; create value from waste; substitute with renewables and natural processes; deliver functionality rather than ownership; adopt a stewardship role; encourage sufficiency; re-purpose the business for society/environment; and develop scaleup solutions (Bocken et al., 2014). Engagement with end customers and stakeholders (Stubbs \& Cocklin, 2008), such as collaborating with local non-governmental organizations to improve integration into the community and understanding of the local culture, is highlighted in order to understand how sustainable business models create value for a broader set of stakeholders (Valkokari et al., 2014).

Sustainable business models and circular business models are closely related literature streams and they can be regarded as a subcategory of business models. A circular business model can be defined as the rationale of how an organization creates, delivers, and captures value with and within closed material loops (Mentink, 2014). The idea is that a circular business model does not need to close material loops by itself within its internal system boundaries, but can also be part of a system of business models that together close a material loop in order to be regarded as "circular" (Mentink 2014). Circular business model innovations are by nature networked: they require collaboration, communication, and coordination within complex networks of interdependent but independent actors/stakeholders. The challenge of re-designing business ecosystems is to find the "win-win-win" setting (Antikainen et al., 2013) 


\title{
A Framework for Sustainable Circular Business Model Innovation
}

\author{
Maria Antikainen and Katri Valkokari
}

that finds a balance between the self-interests of involved actors and thereby influences and facilitates their actions in order to cooperatively shape the circular business model. Yet, in reality neither $100 \%$ circular business models nor $100 \%$ linear business models exist due to physical and practical reasons. In prior literature on the circular economy, the focus has been on identifying characteristics of circular business models based on longevity, renewability, reuse, repair, upgrade, refurbishment, capacity sharing, and dematerialization (Accenture, 2014). Yet, there is a lack of academic literature on the circular economy, especially as it relates to novel business opportunities.

\section{Current tools and methods for circular economy business modelling and challenges}

Over the last decade, the business model has been actively discussed as an important unit of analysis in innovation studies. Overviews of the most important methods and tools for general business model innovation can be found in the (academic) literature. Business model innovation has twofold activities: the design of a new business model or its re-configuration (Massa \& Tucci, 2014). Both academics and practitioners have proposed a multitude of avenues and tactics to support business model innovation. The most well-known tool for business model description is the business model canvas, which is a generic and easy-to-use tool, which has been applied in different industries (Osterwalder \& Pigneur, 2010).

Based on the business model canvas, Sempels (2014) has created a sustainable business canvas that extends the original canvas by proposing 10 elements. In his canvas, he adds the perspective of organizational effectiveness and efficiency, positive and negative externalities, as well as drivers of productivity. Mentink (2014) has conducted an extensive analysis of the existing business modelling tools and their suitability in the context of circular business model innovation. Based on his findings, he proposes the business cycle canvas, which emphasizes the ideas related to the importance of understanding the circularity of the loop. This loop includes the roles of suppliers and stakeholders, as well as the importance of having an integrated business model for the whole supply chain. This approach requires an understanding of each of the actors' motives and how the value is co-created for them. The multiplestakeholder value perspective is also included in the value mapping tool developed by Bocken and colleagues (2015), introducing three forms of value (value captured, destroyed, and missed) and value opportunities for major stakeholder groups (environment, society, customer, and network actors). One of the main benefits of their tool is to raise awareness of the potential for unintended impacts on external stakeholders, as well as to propose alternative solutions that might offer greater alignment between stakeholder interests. Furthermore, the play-it-forward tool (Dewulf, 2010) is also derived from the business model canvas, adding the building blocks for a triple bottom line, which means taking into account the perspectives of sustainability, in other words, integrating environment, business, and society views.

\section{The Framework for Sustainable Circular Business Model Innovation}

Our framework is built upon the ideas and the structure of the business model canvas, other tools, and studies on the circular economy and sustainability. The idea is to provide a generic model for business model innovation to support companies in designing, as well as reconfiguring, their business models.

The whole business ecosystem is changing and the circular economy needs systematic innovation, and therefore, a multilevel analysis is needed. The change towards sustainable and circular business model innovation should integrate elements from macro (global trends and drivers), meso (ecosystem and value co-creation) and micro (company, customers, and consumers) levels (Valkokari et al., 2014). Trends and drivers include the analysis of the business environment and scanning current trends. For example, new legislation might have a significant influence on the business model. The impact of the business model is divided into sustainability costs and benefit, adding the perspective of a triple bottom line to business model development.

The framework includes the idea of continuous iteration with sustainability and circularity evaluation of the business model (Figure 2). These aspects are needed in order to gain factual data about the sustainability of the business model in order to optimize the processes and to understand the dynamics of the processes needed. For example, change in one link in the supply chain may dramatically influence the whole model. The sustainability part of this evaluation can be conducted by using the evolving literature of lifecycle-assessment tools. The circularity perspective focuses on visualization of the model in order to understand the needed actors, relationships, cycle stages, and flows of material and information. For instance, three environmental strategies - closing, narrowing and slowing the loop 


\section{A Framework for Sustainable Circular Business Model Innovation}

\section{Maria Antikainen and Katri Valkokari}

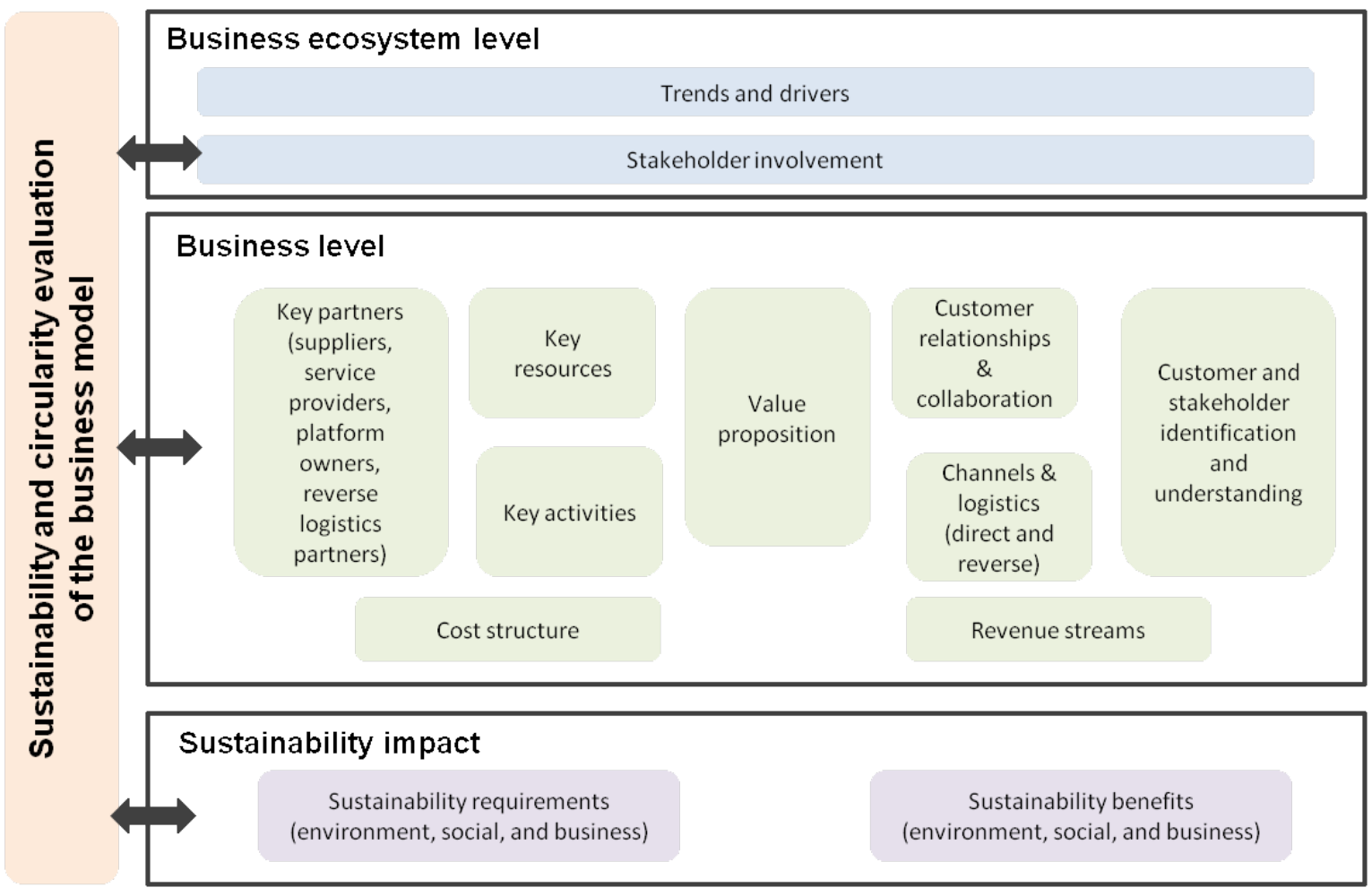

Figure 2. Framework for sustainable circular business model innovation

within circularity, as suggested by Kraaijenhagen, Van Oppen, and Bocken (2016) - can also be evaluated. Or, when taking a more quantitative approach to the evaluation of circularity impacts, there is a toolkit for circularity indicators currently being built in the European Union project called "The Circularity Indicators Project" by the Ellen MacArthur Foundation (2015).

\section{Case Example}

\section{Case selection and methodology}

A single case study method was chosen as the method for the study. A case study approach is the most suitable in situations where the main research questions are depictive (Yin, 2014). A case study is also known as a method where data triangulation is often used to increase the quality of the study. Instead of using sampling methods, the case selection maximizes what can be learned in the period of time available for the study. The case we chose for this study was one innovative startup company implementing a circular business model in Finland. The case company was already familiar to us through collaborations with the owner in our current research programme. Thus, we had easy access to the case and at the same time we were able to utilize our earlier knowledge.
Our main data was collected in a three-hour interview and discussion session with the entrepreneur. We had three researchers representing different backgrounds (consumer research, environmental impacts and business, and innovation) participating in the session. We used a semi-structural research guide, however, the session was more similar to a discussion than an interview. The session was recorded and one of the interviewers also was responsible for taking notes. In addition to the interview, secondary data was derived from the company's presentation material, websites, and several earlier informal discussions with the entrepreneur.

\section{Case description}

Company $\mathrm{X}$ is a social enterprise established in 2011 and located in Finland. It provides fully scalable solutions for accelerating product reuse and recycling. One of its main services is the digitalized concept aimed at recycling centres or other second-hand market actors selling, buying, and swapping products. The concept enables recycling centres to increase the efficiency of the process of adding new products for sale on the Internet. Its aim is also to accelerate the flow of the products by justifying their price based on the time they have been available. The concept is also easy to 


\section{A Framework for Sustainable Circular Business Model Innovation}

\section{Maria Antikainen and Katri Valkokari}

use and this is important because recycling centres employ people with various skills sets and backgrounds.

\section{Analysis and results}

The analysis is presented in Figure 3. The entrepreneur was very familiar with ecosystem thinking, trends, and drivers. Value propositions for different stakeholders took most of the time during discussions. Particularly, understanding end user needs and value creation for consumers was regarded as beneficial and seemed to open new insights for the entrepreneur. Also, the different possibilities for revenue models were discussed extensively. All in all, the framework seemed to work well in this case, being still rather simple. The framework can be filled in during a three-hour period, but each of the blocks could easily take more than three hours of thinking and brainstorming about different options and evaluating them. In addition, the sustainability and circularity iteration and more detailed cost-benefit analysis with the business model will take time, and is therefore beyond the scope of this article. As such, the framework can be regarded as a good way for communicating a business model to stakeholders, including financers and the media.

\section{Findings and Conclusions}

Currently, there is a lack of frameworks for supporting business model innovation in companies in the context of a circular economy. The current tools do not offer the needed understanding in the changing business environment and breaking up of current value chains. Furthermore, the impact of the circular economy models and sustainability should be understood through value creation for all stakeholders. The challenge of re-designing business ecosystems is to find the "win-win-win" setting (Antikainen et al., 2013) that balances the self-interests of involved actors and sustainability impacts. Thereby, the need for change communicated through business model influences and facilitates their actions in order to shape activities towards joint goals. Based on the results, instead of a single business model innovation, the role of systemic innovations was emphasized. Thus, re-design is often challenging for established companies within an existing business ecosystem and model, and therefore newcomers quite often are the ones who are able to disrupt and re-design the value chains as shown by the well-known examples of Uber or Airbnb.

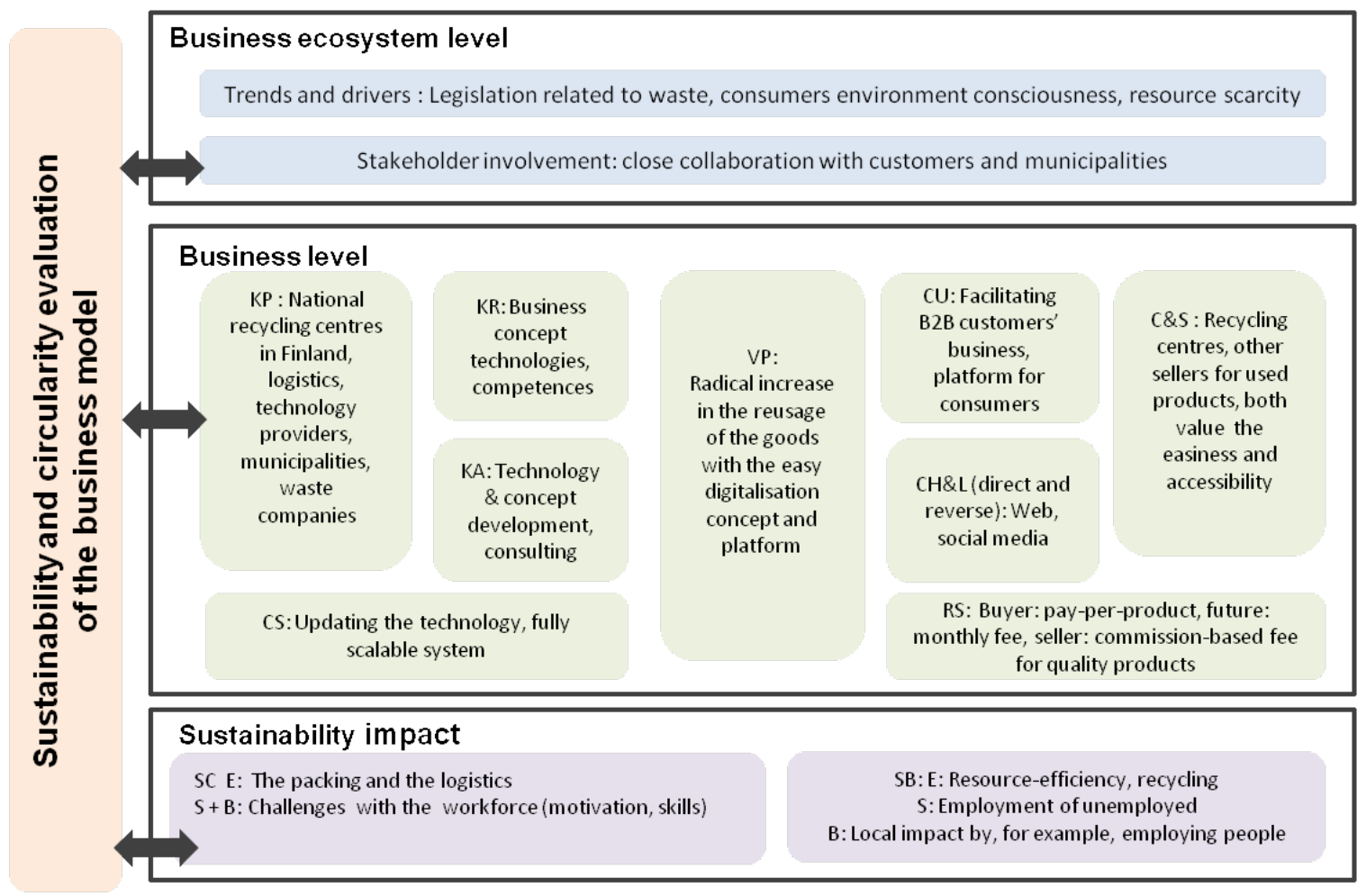

Figure 3. Framework for sustainable circular business model innovation: Case example of Company X 


\title{
A Framework for Sustainable Circular Business Model Innovation
}

\author{
Maria Antikainen and Katri Valkokari
}

Furthermore, business model innovation practices often focus on incremental changes in areas such as key activities, key resources, and distribution channels. By its definition, system innovation, which is often needed in sustainable circular business models, should be considered at the multiple levels of system, which encompasses the cradle-to-cradle use of resources. A systems perspective to business model innovation exhaustively and holistically considers the entire system, which has several levels that need to be considered. Therefore, the suggested framework complements current business model tools by adding the business ecosystem level, analysis of sustainability costs and benefits, as well as iterative cycles of sustainability and circularity evaluation (see Figure 3).

There are several interesting paths to take related to business model innovation in a circular economy. In order to innovate in a circular economy, taking a multidisciplinary perspective plays a central role; thus, the framework presented combines views from foresight, business, consumers, and sustainability. The findings of this research describe the emerging practices for business model innovation based on a circular economy and thereby point to several research issues that appear worthy of further study. First, the framework should be tested in several other cases with different companies and industries. Second, longitudinal studies could straighten out the key stages of business model innovation processes by design or re-configuration. Third, especially for the sustainability and circularity evaluation parts/tasks in the framework, novel methods need to be developed in order to facilitate continuous iteration.

\section{Acknowledgements}

This research has been conducted as a part of the AARRE (Capitalising on Invisible Value - User-Driven Business Models in the Emerging Circular Economy) project. The authors would like to express their gratitude to the Green Growth Programme of the Finnish Funding Agency for Innovation (Tekes), Technical Research Centre of Finland (VTT), and other parties involved in AARRE project for their financial support.

An earlier version of this article was presented at the 2016 ISPIM Innovation Forum in Boston, United States of America, March 13-16. ISPIM (ispim.org) - the International Society for Professional Innovation Management - is a network of researchers, industrialists, consultants, and public bodies who share an interest in innovation management.

\section{About the Authors}

Maria Antikainen is a Senior Scientist at VTT (Technical Research Centre of Finland) in the Business, Innovation and Foresight research area. She is also an Adjunct Professor in the Department of Industrial Management at Tampere University of Technology, where she specializes in innovation in business networks. Maria's main research areas are the circular economy and sustainable business models and new business opportunities enabled by the Internet of Things. During her 14 years of experience in research, Maria has been initiating, conducting, and managing numerous research and development projects with research partners, companies, and public funding organizations such as Tekes and the European Union. Maria holds a PhD in Technology Management from the Tampere University of Technology (2011) and a PhD in marketing from the University of Tampere (2007).

Katri Valkokari is a Principal Scientist at VTT (Technical Research Centre of Finland) in the Business, Innovation and Foresight research area. Over the past 15 years, she has carried out several development projects concerning different networked business arrangements (ecosystems, networks, partnerships, and firms). In 2009, Katri completed her doctoral thesis on business network development. She has published several international and national articles in the research areas of business network management, collaboration, organizational knowledge, innovation management, and sustainability.

\section{References}

Antikainen, M., Valkokari, K., Korhonen, H., \& Wallenius, M. 2013. Exploring Networked Innovation in Order to Shape Sustainable Markets. Paper presented at the XXIV ISPIM Conference, June 16-19, Helsinki, Finland.

Aminoff, A., Valkokari, K., \& Kettunen, O. 2016. Mapping Multidimensional Value(s) for Co-Creation Networks in a Circular Economy. Forthcoming in Proceedings of PRO-VE2016 Conference. Springer IFIP AICT Series.

Bocken, N. M. P., Short, S. W., Rana, P., \& Evans, S. 2014. A Literature and Practice Review to Develop Sustainable Business Model Archetypes. Journal of Cleaner Production, 65: 42-56. http://dx.doi.org/10.1016/j.jclepro.2013.11.039

Bocken, N. M. P., Rana, P., \& Short, S. W. 2015. Value Mapping for Sustainable Business Thinking. Journal of Industrial and Production Engineering, 32(1): 67-81.

http://dx.doi.org/10.1080/21681015.2014.1000399 


\section{A Framework for Sustainable Circular Business Model Innovation}

\section{Maria Antikainen and Katri Valkokari}

Boons, F., Montalvo, C., Quist, J., \& Wagner, M. 2013. Sustainable Innovation, Business Models and Economic Performance: An Overview. Journal of Cleaner Production, 45: 1-8. http://dx.doi.org/10.1016/j.jclepro.2012.08.013

Chesbrough, H. 2010. Business Model Innovation: Opportunities and Barriers. Long Range Planning, 43(2-3): 354-363. http://dx.doi.org/10.1016/j.lrp.2009.07.010

Cooper, J. S., \& Fava, J. A. 2006. Life Cycle Assessment Practitioner Survey: Summary of Results. Journal of Industrial Ecology, 10(4): $12-14$. http://dx.doi.org/10.1162/jiec.2006.10.4.12

Ellen MacArthur Foundation. 2012. Towards the Circular Economy: Economic and Business Rationale for an Accelerated Transition. Isle of Wight, United Kingdom: Ellen MacArthur Foundation.

Ellen MacArthur Foundation. 2015. Circularity Indicators Project. Ellen MacArthur Foundation. Accessed July 1, 2016: http://www.ellenmacarthurfoundation.org/programmes/insight/c ircularity-indicators

European Commission. 2016. Closing the Loop: An EU Action Plan for the Circular Economy. European Commission, June 28, 2016. Accessed July 1, 2016: http://ec.europa.eu/environment/circulareconomy/index_en.htm

Hertwich, E. G. 2005. Consumption and the Rebound Effect. Journal of Industrial Ecology, 9(1-2): 85-98. http://dx.doi.org/10.1162/1088198054084635

Kraaijenhagen, C., van Oppen, C., \& Bocken, N. M. B. 2016. Circular Business: Collaborate \& Circulate. Amersfoort, The Netherlands: Circular Collaboration.

Lacy, P., Cooper, T., Hayward, R., \& Neuberger, L. 2010. A New Era of Sustainability: UN Global Compact-Accenture CEO Study 2010. New York: United Nations.

http://www.unglobalcompact.org/docs/news_events/8.1/UNGC_ Accenture_CEO_Study_2010.pdf

Lovins, A., Lovins, L., \& P. Hawken. 1999. A Road Map for Natural Capitalism. Harvard Business Review, 85(7/8): 145-158.

Massa, L., \& Tucci, C. L. 2014. Business Model Innovation. In M. Dodgson, D. M. Gann, \& N. Phillips (Eds.), Oxford Handbook of Innovation Management: 420-441. Oxford: Oxford University Press. http://dx.doi.org/10.1093/oxfordhb/9780199694945.013.002
McDonough, W., \& Braungart, M. 2002. Cradle to Cradle: Remaking the Way We Make Things. New York: North Point Press.

Mentink, B. 2014. Circular Business Model Innovation: A Process Framework and a Tool for Business Model Innovation in a Circular Economy. Master of Science in Industrial Ecology Thesis, Delft University of Technology \& Leiden University.

Osterwalder, A., \& Pigneur, Y. 2010. Business Model Generation: A Handbook for Visionaries, Game Changers, and Challengers. Hoboken, NJ: Wiley.

Wells, P., \& Seitz, M. 2005. Business Models and Closed-Loop Supply Chains: A Typology. Supply Chain Management, 10(4): 249-251. http://dx.doi.org/10.1108/13598540510612712

Sempels, C. 2014. Implementing a Circular and Performance Economy through Business Model Innovation. In A New Dynamic: Effective Business in a Circular Economy. Isle of Wight, United Kingdom: Ellen MacArthur Foundation

Stahel, W. 2014. The Business Angle of a Circular Economy: Higher Competitiveness, Higher Resource Security and Material Efficiency. In A New Dynamic: Effective Business in a Circular Economy. Isle of Wight, United Kingdom: Ellen MacArthur Foundation

Stubbs, W., \& Cocklin, C. 2008. Conceptualizing a 'Sustainability Business Model'. Organization \& Environment, 21(2): 103-127. http://dx.doi.org/10.1177/1086026608318042

Tukker, A., \& Tischner, U., 2006. Product-Services as a Research Field: Past, Present and Future. Reflections from a Decade of Research. Journal of Cleaner Production,14(17): 1552-1556. http://dx.doi.org/10.1016/j.jclepro.2006.01.022

Yin, R. 2014. Case Study Research: Design and Methods (5th ed). Los Angeles, CA: Sage.

Valkokari, K., Valkokari, P., Palomäki, K., Uusitalo, T., Reunanen, M., Macchi, M., Rana, P., \& Liyanage, J. P. 2014. Road-Mapping the Business Potential of Sustainability within the European Manufacturing Industry. Foresight, 16(4): 360-384. http://dx.doi.org/10.1108/FS-05-2012-0037 